\title{
Corrigendum
}

\section{Efficacy and Tolerability of an mGlu2/3 Agonist in the Treatment of Generalized Anxiety Disorder}

Eduardo Dunayevich, Janelle Erickson, Louise Levine, Ronald Landbloom, Darryle D Schoepp and Gary D Tollefson

Neuropsychopharmacology (2008) 33, 2549; doi:I 0.I 038/sj.npp.I 301622

Correction to: Neuropsychopharmacology advance online publication 22 August 2007; doi: 10.1038/sj.npp.1301531

Following the online publication of this article, the authors have provided the following affiliation corrections: $\mathrm{Dr}$
Louise Levine retired from Eli Lilly and Co.; she is not affiliated with Merck and Co. When this study was conducted, she and all other authors were employees of Eli Lilly and Co.' 